\title{
CORPO COMO CONTEXTO-DE-OCORRÊNCIA DE METAPRAGMÁTICAS SOBRE O PORTUGUÊS EM SOCIALIZAÇÕES DE ESTUDANTES MIGRANTES PARA O BRASIL
}

\author{
Joana Plaza Pinto* \\ Universidade Federal de Goiás \\ Faculdade de Letras \\ Departamento de Língua Portuguesa e Linguística \\ Goiânia, GO, Brasil
}

\begin{abstract}
Resumo: Este artigo analisa projeções metapragmáticas sobre o português em narrativas de estudantes migrantes no Brasil. Produzidas em pesquisa etnográfica longitudinal, as narrativas focaram nas trajetórias de vinda, recepção e permanência migratória e suas posições diante do português. Para esta análise, são centrais as interpretações de Povinelli sobre os estudos metapragmáticos e de Ochs sobre socialização pela linguagem. A análise aponta que a socialização das normas institucionais é fundamental nas formulações explícitas sobre o valor do português de quem narra e a avaliação da experiência estudantil. Essas metapragmáticas orientam a interpretação dos valores linguísticos do que é dito, para quem, por que e em que circunstâncias, enquanto o corpo que fala projeta-se e projeta suas/seus interlocutoras/es nessa interpretação. O corpo é um contexto-de-ocorrência para os recursos semióticos - o lugar em que se constituem condições para se dizer certas coisas e o lugar que é constituído pelas coisas que se diz.
\end{abstract}

Palavras-chave: Migração estudantil. Corpo. Socialização. Metapragmática. Português.

1 INTRODUÇÃO

Este artigo discute diferentes projeções metapragmáticas sobre o "português"1 em narrativas de estudantes universitárias(os) migrantes de partes opostas do hemisfério sul em direção ao Centro-oeste brasileiro. Construídas no contexto de uma pesquisa etnográfica longitudinal com estudantes migrantes, as narrativas focaram nas suas trajetórias de vinda para o Brasil, recepção e permanência em uma universidade pública, e, neste contexto, suas avaliações das práticas linguísticas em geral e do "português" em particular.

Para interpretar as metapragmáticas explícitas e implícitas, me baseio predominantemente nas discussões de Elizabeth Povinelli (2016) sobre função

\footnotetext{
* Professora Associada. Pesquisadora Bolsista de Produtividade em Pesquisa do CNPq. ORCID: <http://orcid.org/0000-0001-8052-9390>. E-mail: joplazapinto@ufg.br.

${ }^{1}$ Assumo desde o início o nome "português" como atribuído a um conjunto de práticas heterogêneas, ao mesmo tempo regulado por práticas de padronização e regulamentação próprias dos territórios colonizados. O uso de aspas duplas visa destacar esse gesto performativo de nomeação/invenção dessas práticas como "uma língua". Para mais discussões sobre essa posição, cf. Makoni e Pennycook (2007), Mignolo (2003) e Moita Lopes (2013).
}

PINTO, Joana Plaza. Corpo como contexto-de-ocorrência de metapragmáticas sobre o português em socializações de estudantes migrantes para o Brasil. Linguagem em (Dis)curso - LemD, Tubarão, SC, v. 18, n. 3, p. 751-768, set./dez. 2018. 
metapragmática e discurso metapragmático e de Elinor Ochs (1991, 2000, 2006) sobre socialização pela linguagem. Com foco em problemas diferentes, ambas as autoras estão preocupadas com aspectos do funcionamento da linguagem que nos torna sujeitos humanos. Povinelli (2016, p. 209) está especialmente focada nas "condições semânticas e pragmáticas, metassemânticas e metapragmáticas, que fazem com que sejamos e nos tornemos sujeitos humanos.", enquanto Ochs (2000, p. 232) foca seu interesse no papel da linguagem nas convenções sociais de uma comunidade e nas condições como "os membros mais ou menos experientes aprendem uns com os outros através da implementação criativa de recursos linguísticos para navegar e construir a condição humana".

Para fins da análise que apresento aqui, adoto a definição de metapragmáticas como o conjunto de recursos semióticos que orientam nossa interpretação, não apenas dos valores linguísticos do que é dito, para quem, por que e em que circunstâncias, mas também da ordenação indexical no qual o corpo que fala se projeta e projeta suas/seus interlocutoras/es (POVINELLI, 2016). A partir disso, desenvolvi a ideia de que o corpo é uma espécie de contexto-de-ocorrência para os recursos semióticos - o lugar em que se constituem condições para se dizer certas coisas e o lugar que é constituído pelas coisas que se diz (SCOLLON; SCOLLON, 2003).

Em seu artigo mais conhecido sobre metapragmática, Silverstein (1993) discute a dialética pragmática-metapragmática e menciona a relação entre a projeção das categorias pragmáticas nas formas metapragmáticas. Ele afirma que

\begin{abstract}
A metapragmática fortemente explícita, onde o registro metapragmático funcional emerge no texto denotacional (portanto segmentável como texto-sentenças denotacionais), é associável a categorias pragmáticas de tipo semiótico particular: tais categorias são altamente pressupostas de algum estado de coisas contextual em cada ocorrência de uso, em oposição a altamente implicadas; tais categorias são denotavelmente localizáveis na organização gramatical referencial-e-predicativa ao longo da dimensão whorfiana de aberto a escondido (Whorf 1956a [1937]: 88-93), embora possam funcionar semioticamente na indexicalidade não-denotacional; e, no caso perfeito, essas categorias são inerentemente metapragmáticas. Por esses critérios, um sinal pragmático que marca o estado de coisas de seu contexto de ocorrência meramente, que é expresso em um elemento de superfície formal isolável e estruturalmente contínuo da estrutura gramatical de um texto-sentença (raiz, afixo, palavra, clítico, frase contínua etc.), e que denota, assim como indicia, e, de fato, denota o que indicia (pressupõe), é o mais provável dos sinais pragmáticos a serem reguláveis por uma metapragmática fortemente explícita - por exemplo, o léxico de verbos performativos numa língua. (SILVERSTEIN, 1993, p. 54-55)
\end{abstract}

O corpo é o recurso semiótico (SCOLLON; SCOLLON, 2003) e performativo (BUTLER, 1997; FELMAN, 1980) com mais probabilidade de regulação por uma metapragmática. Como primeiro índice de interpretação na interação face-a-face, o corpo é decodificado como performativo, mais evidentemente a voz (BAUGH, 2003), mas também a cor da pele, como argumenta Sales Jr. (2006, p. 232): “A cor da pele ocupa o lugar do significante central que conecta, organiza e totaliza todos os demais elementos". É essa exigência da semiose corporal que precisa ser qualificada na situacionalidade de cada evento comunicativo, como pressuposto ou como implicado/acarretado de algum estado de coisas contextual. 
Já que na dialética pragmática-metapragmática certas categorias pragmáticas pressupõem algum estado-de-coisas contextual e denotam o que indexam, podemos entender as projeções metapragmáticas como certas regulações metapragmáticas fortemente explícitas projetadas por categorias pragmáticas.

Uma análise desses recursos semióticos, incluindo o corpo, que organizam a dialética pragmática-metapragmática, certamente pode colaborar para a compreensão da socialização, o processo pelo qual iniciantes ganham conhecimento e habilidades relevantes para a adesão a um grupo social. Para Ochs (1991), este processo é realizado em grande parte através de práticas de linguagem e interações sociais que envolvem iniciantes em uma variedade de papéis comunicativos e situacionais. A socialização é um processo dinâmico e sinérgico que é realizado em conjunto, momento a momento, durante o tempo de interação.

Essa dinamicidade da socialização conjunta requisita regulações metapragmáticas fortemente explícitas, especialmente quando o evento comunicativo em ocorrência tem por objetivo a narrativa, como é o caso da entrevista qualitativa em etnografia longitudinal. Com grande potencial democrático (HYMES, 1996) e contra-hegemônico (BLOMMAERT; JIE, 2010), a etnografia aqui apresentada promoveu uma observação compreensiva, com participação e descrição das costuras sutis entre os microcontextos focalizados e os macrocontextos indiciados (OCHS, 1992), cada narrativa inserida numa rede específica de antecipações, desejos e ações (OCHS, 2006). Com uma visão dinâmica e performativa de linguagem, na calibragem e adaptação ao longo do campo, as oportunidades narrativas registradas em áudio complementaram as observações multissituadas (tanto espaços múltiplos etnografados quanto com as diferentes formas de registros desses espaços em diferentes locais por onde circulam as(os) participantes, como propõe Briggs (2007)), ao mesmo tempo que permitiram uma atenção detalhada à heterogeneidade e singularidade de cada narrativa e sua conexão com trajetórias textuais e corporais em jogo.

Isso me leva a apresentar, da forma mais sintética possível, a pesquisa de onde selecionei os excertos sob análise neste artigo, a história dos dados como contexto crítico (BLOMMAERT, 2008). Em seguida, apresentarei a análise em dois focos: o primeiro, a forma como a função metapragmática faz emergir os padrões de socialização em ação nas narrativas; o segundo, a forma como certas regulações metapragmáticas fortemente explícitas projetam o valor do "português" de quem fala e sua conexão com categorias de diferença corporal (BRAH, 2006; PISCITELLI, 2008). Finalizo com algumas consequências desses dois focos, tendo as projeções metapragmáticas como chave para a compreensão dos corpos como contexto-de-ocorrência.

\section{A ETNOGRAFIA E SUA HISTÓRIA CRÍTICA}

Trata-se aqui de uma etnografia longitudinal multissituada em uma universidade brasileira pública e gratuita ${ }^{2}$, com vinculação federal, a segunda maior universidade da

\footnotetext{
${ }^{2}$ Esta pesquisa foi submetida e aprovada pelo Comitê de Ética em Pesquisa da Universidade Federal de Goiás, Protocolo 50768715.7.0000.5083, Parecer 1.369.610 de 15/12/2015. 
região Centro-oeste do Brasil e a vigésima primeira do país no ranking de universidades brasileiras, com cerca de 24 mil estudantes na graduação em seus 150 cursos. No entanto, tem em média de 35 a 40 estudantes estrangeiros(as) na graduação regular, com vínculo de longo termo, através de um convênio. As(os) demais estudantes estrangeiras(os) matriculadas(os) na graduação são parte de programas de mobilidade transnacional de curta duração (intercâmbios diversos).

O convênio em questão é o Programa Estudantes-Convênio de Graduação (PECG). Trata-se de um Programa de oportunidades de formação superior para cidadãs(os) de países em desenvolvimento com os quais o Brasil mantém acordos educacionais e culturais - a lista inclui países de África, Ásia, América Latina e Caribe. O PEC-G é um programa multiministerial, envolvendo o Ministério das Relações Exteriores e o Ministério da Educação, em parceria com universidades públicas federais, estaduais e particulares.

As características do PEC-G como programa de trânsito internacional em direção ao Brasil afetam de forma complexa o perfil das(os) participantes da pesquisa. Para inscrição, elas(es) precisam apresentar certificado de conclusão do ensino médio ou curso equivalente e comprovante de proficiência em língua portuguesa, sendo obrigatório o Celpe-Bras (Certificado de Proficiência em Língua Portuguesa para Estrangeiros) para estudantes oriundas(os) de país não lusófono ${ }^{3}$. São selecionadas preferencialmente pessoas inseridas em programas de desenvolvimento socioeconômico, acordados entre o Brasil e seus países de origem. Os acordos determinam a adoção, pelo aluno, do compromisso de regressar ao seu país e contribuir com a área na qual se graduou.

Duas características destacadas na página eletrônica do programa são que a(o) aluna(o) estrangeira(o) selecionada(o) para o programa cursa gratuitamente a graduação no Brasil, ao mesmo tempo em que uma das exigências é que a(o) candidata(o) prove no ato da inscrição para seleção que é capaz de custear suas despesas no Brasil. Essas duas características impactam contraditoriamente o perfil de estudantes: há tanto aquelas(es) que recebem recursos financeiros de sua família de origem - "só dou despesa", escreveu à mão uma das participantes em resposta à pergunta de múltipla escolha "Como você participa, com o seu salário, na vida econômica da sua família em seu país de origem ou no Brasil?" do questionário de perfil; há aquelas(es) que informam fontes não realistas durante o processo seletivo, com o único fim de ser aprovada(o), e acabam buscando alternativas econômicas quando chegam ao Brasil, incluindo apoio estudantil de vários tipos (bolsas de permanência, moradia estudantil, subsídios para restaurante universitário), bolsas acadêmicas (iniciação científica), venda de produtos diversos (especialmente vestuário) e as duas bolsas dirigidas ao PEC-G (Promisaes e Mérito). Com sentidos contraditórios nas narrativas, a gratuidade do ensino superior é um atrativo para a migração em direção ao Brasil, enquanto a "capacidade de custear despesas no Brasil" é mencionada como exigência não realista e incompatível com os objetivos do convênio.

As primeiras aproximações pré-campo foram realizadas com alunas do PEC-G matriculadas no curso obrigatório "Leitura e Produção Textual” (2011.1), com retorno

\footnotetext{
${ }^{3}$ Desde o Edital de Convocação n. 13, 30/04/2015, para entrada no PEC-G em 2016, é exigido o CelpeBras de todas(os) as(os) candidatas(os), independente da sua nacionalidade. No entanto, esta mudança não afetou nenhum(a) dos(as) atuais participantes desta pesquisa, que entraram antes de 2016.
} 
das mesmas alunas no curso de núcleo livre "Língua, Escrita e Identidade" (2011.2). Em momento posterior, aproximei-me de várias alunas e alunos PEC-G nas duas ofertas do curso de núcleo livre "Práticas Interculturais de Leitura e Produção Textual" (2014.2 e 2015.1), oferecido preferencialmente para "estrangeiros e cotistas" ${ }^{4}$ a pedido da PróReitoria de Graduação (PROGRAD) através de sua Coordenação de Inclusão e Permanência ${ }^{5}$. Foram essas experiências iniciais, com fortes vínculos com as alunas e alunos desses cursos, que me levaram a desenhar a pesquisa.

As(os) participantes da pesquisa até o momento são seis mulheres e dois homens, com idades entre 19 e 27 anos à época da entrada na pesquisa, advindos(as) de países conveniados das seguintes regiões: Caribe, América Central, América do Sul, África e Leste Asiático, integrantes de cursos de graduação de diversas áreas: Saúde, Biológicas, Agrárias, Engenharias, Sociais Aplicadas, Letras/Artes, em diferentes etapas: de iniciante a formando(a).

Foram realizadas observações de atividades no Centro de Convivência, espaço institucional com presença de estudantes PEC-G (desde 2015.2); observação participante (2016-2018) em eventos acadêmicos com a presença de participantes, como encontro semestral de acompanhamento de estudantes PEC-G e outros eventos acadêmicos; participação (2016-2017) em eventos pessoais a convite de participantes, como festa de formatura e chá de berço, incluindo visitas domiciliares mútuas em diferentes ocasiões, sob convite prévio ou sob encontro casual. Sendo moradora do mesmo bairro em que mora a maioria das participantes ( 5 de 8 ), na vizinhança do campus principal da universidade, encontro com frequência especialmente quatro delas nas redondezas. Além disso, quatro foram em momentos diferentes da sua vida acadêmica estudantes das minhas turmas.

Essas práticas de observação e participação se combinam com práticas de observação online, ou seja, acompanhamento de postagens no grupo PEC-G da universidade, um grupo fechado para o qual fui convidada pelo então coordenador do PEC-G da universidade; acompanhamento de postagens individuais de participantes em diferentes redes sociais e blogs; e, por fim, comunicação regular por grupo fechado em rede social, gerado em 2017.2 por ocasião da segunda oficina da pesquisa.

Por fim, também têm sido feitos registrados gravados e filmados em forma de entrevistas individuais - 9 entrevistas individuais com 8 participantes (10:55 de áudio; realizadas de 2016 a 2018); grupo de discussão - 1 grupo com 2 participantes (2:09 de áudio, realizado em 2016); e oficinas biográficas "linha da vida" 6 - 2 oficinas com 4 participantes (3:35 de áudio e filmagem; realizadas em 2017). O coordenador do PEC-G na universidade na ocasião também foi entrevistado uma vez para fins de

\footnotetext{
${ }^{4} \mathrm{O}$ público preferencial da oferta era determinado pela própria PROGRAD, não por mim ou pelo colega docente parceiro da disciplina, Prof. Dr. André Marques do Nascimento, a quem sou muito grata pela parceria, generosidade e engajamento de sempre.

${ }^{5}$ Desde janeiro de 2018, esta Coordenação não faz mais parte da PROGRAD, sendo ligada diretamente ao Gabinete da Reitoria.

${ }^{6}$ Esta oficina é a adaptação de uma oficina feminista para fins de geração de material etnográfico e é detalhada e analisada em outras publicações submetidas ou em prelo desta pesquisa.
}

PINTO, Joana Plaza. Corpo como contexto-de-ocorrência de metapragmáticas sobre o português em socializações de estudantes migrantes para o Brasil. Linguagem em (Dis)curso - LemD, Tubarão, SC, v. 18, n. 3, p. 751-768, set./dez. 2018. 
contextualização das práticas institucionais particulares da universidade específica em relação ao programa (1:20 de áudio; realizada em 2016).

A transcrição constitui parte integrante do procedimento de análise. Seguimos como parâmetro de transcrição uma adaptação das convenções de Mary Bucholtz (2000) e Rodrigo Borba (2014) (Anexo) para uma representação de aspectos de produção da fala: entonacionais, temporais e de velocidade da produção vocal.

Este artigo analisa fundamentalmente duas entrevistas individuais, tendo como contexto crítico a história da geração do material empírico e as observações participantes.

\section{OS DOIS CASOS SOB ANÁLISE}

Dados os limites deste artigo, optei por focar dois casos que se destacam no conjunto do material empírico como extremos opostos e buscar as lições sobre projeções metapragmáticas em socializações migratórias que tais casos nos oferecem. As duas entrevistas foram escolhidas porque indiciam posições e avaliações nas extremidades de um continuum heterogêneo de valoração, reconhecimento e autorreconhecimento de seus usos linguísticos e a correlação entre tais valorações e as categorias de diferença corporal na experiência migrante estudantil.

As duas pessoas participantes aqui apresentadas recebem codinomes que elas mesmas escolheram quando aceitaram participar da pesquisa.

Jogador veio de uma cidade paraguaia na fronteira nordeste do seu país com o sudoeste do Brasil, a cerca de mil e duzentos quilômetros da cidade universitária em que está matriculado. Ele se apresentou na pesquisa como um homem "amarelo" - ainda que eu o reconheça como um homem branco, sem traços de fenótipo indígena ou oriental evidentes - de 21 anos, solteiro, de uma família de quatro irmãos, com vários índices narrativos que reconhecemos como "classe média": a mãe terminou o ensino superior e o pai terminou o ensino médio; eles tinham empregada doméstica em casa e TV a cabo; sempre que o calendário acadêmico permite, ele viaja para o Paraguai. Ele se mudou para o Brasil em 2015 e cursa Engenharia Civil. Mora numa das Casas de Estudante da universidade, num campus diferente do campus principal, onde dou aula e moro; além disso, ele tem uma pequena bolsa-alimentação da universidade, auxílio para fazer três refeições diárias no restaurante universitário. Sua família também envia recursos financeiros, mas ele nunca disse quanto nem para que fins.

Jogador está inserido em várias atividades de lazer decorrentes do convívio universitário, como a Atlética (agrupamento de alunos voltado para atividades de lazer e esportivas, o que talvez explique sua escolha de codinome) e vários tipos de festas planejadas entre alunos. Ele conta que tem muitos amigos - todos os mencionados são nomes masculinos - e conhece boa parte da região em torno da capital porque já visitou várias cidades do interior do estado de onde vieram seus colegas de faculdade, sempre a convite e na companhia desses. Afirma espontaneamente que gosta muito dos brasileiros e se sente confortável no Brasil. Eu conheci Jogador num encontro semestral de estudantes do PEC-G; ao saber da pesquisa, ele me procurou ao final do encontro para se oferecer para fazer parte. Além disso, tomou a iniciativa de me pedir para entrevistá-lo 
uma segunda vez, antecipando uma etapa da pesquisa. Ele sempre se mostrou muito solícito, interessado na pesquisa, generoso em seu tempo e disponível para responder a todas as perguntas. Todas as duas vezes em que foi entrevistado, ele me pediu para ser entrevistado no quarto onde mora na Casa de Estudante. Jogador é sempre simpático e engajado na conversa. É um participante que vejo predominantemente em ocasiões programadas, por causa da distância das nossas moradias e do fato de que ele frequenta outro campus. Mesmo assim, encontrei com ele na festa de chá de berço de um outro participante da pesquisa; foi a única vez em que conversamos presencialmente de forma não programada desde que ele integrou a pesquisa. As demais ocasiões de conversas não programadas foram feitas por aplicativo de bate-papo, uma ocasião em que ele me consultou sobre regras de transferência de curso e outra em que o consultei sobre a situação de segurança das proximidades em que ele mora em função de uma forte chuva na cidade. Dentre as(os) participantes da pesquisa, Jogador é quem narra mais positivamente sua experiência de recepção no Brasil e na universidade: ele veio para o Brasil acompanhado da mãe e foi alocado no mesmo dia de chegada na Casa de Estudante onde mora até hoje; nessa ocasião a mãe ficou hospedada na casa de conhecidos paraguaios na cidade e pôde dar suporte afetivo e financeiro nos primeiros dias. Ele considera que aprendeu muito com a experiência até o momento e que sempre foi bem tratado na sua unidade de ensino e entre colegas, interpretando o uso da expressão "Paraguai" para se referir a ele como uma brincadeira. Sempre que escuto suas narrativas afortunadas fico curiosa para saber como ele contaria sua história para outra pessoa, me sentindo muitas vezes representante da instituição enquanto ele superestima cada passo dado dentro da universidade e subestima experiências que eu mesma enquadro como xenófobas.

Arry se apresentou na pesquisa como uma mulher parda do Timor Leste de 25 anos, solteira, de uma família de dois irmãos, cujos pais nunca foram à escola. Ela veio para o Brasil para estudar Farmácia, bem diferente do curso de Arquitetura que ela cursou por três semestres no Timor Leste numa universidade administrada por indonésios. Ela veio para o Brasil em 2013 e desde então nunca mais voltou a seu país de origem. Sua estadia no Brasil é financiada pelo governo leste-timorense e faz parte do conjunto de iniciativas do Acordo de Cooperação Educacional entre o Governo da República Democrática de Timor Leste e o Governo da República Federativa do Brasil, assinado em Díli, em 20 de maio de 2002. Ela mora numa pequena casa alugada na mesma rua e quarteirão que eu, a algumas casas de distância. Foi nesta rua, em algum momento de 2015, que conheci Arry: ela me foi apresentada por outra participante da pesquisa, Ntchalá, minha ex-aluna na disciplina de núcleo livre, hoje já formada em Ecologia e Análises Ambientais. As duas passavam diante de minha casa quando reconheci e cumprimentei Ntchalá, que me apresentou Arry explicando "estamos aqui lutando com o português, professora". Essa metapragmática explícita no meu encontro introdutório com Arry marcou a forma como leio e interpreto sua participação, pois eu mesma procurei-a e convidei-a a integrar a pesquisa. Eu estava desde este momento muito interessada em entender o que significava para ela essa experiência de "luta com o português". Na casa de Arry, que conheci pela primeira vez quando fui entrevistá-la, há um grande mapa-mundi perto da mesa da cozinha e nele ela me mostrou os locais por onde passou para chegar ao Brasil e a distância entre o Brasil e o Timor Leste. Há ainda anotações e lembretes em dois 
diferentes quadros na parede, tanto em escrita alfabética latina em língua portuguesa quanto em outra língua que desconheço. No intuito de respeitar seu espaço em minha primeira e única visita dentro de sua casa, nunca perguntei a Arry que língua era aquela nos quadros - pode ser Tetum ou Malaio, duas das línguas que ela declarou usar recorrentemente. Ela mora sozinha há mais de dois anos e namorava outro lestetimorense, que mora no Ceará, também estudante universitário migrante. Eles se viam em visitas anuais mútuas. Eu conheci o namorado de Arry numa dessas ocasiões em que nos encontramos na nossa rua e os dois me visitaram. Visitei também Arry no laboratório do curso de Farmácia, no qual ela começou um estágio em 2017, assim como tive a chance de oferecer eventuais caronas quando nos cruzamos em nossa rua ou redondezas. Arry é muito polida e gentil. Desde que a conheci, sinto afeto e empatia por ela, me identifico com sua solidão e me solidarizo com sua vulnerabilidade como mulher sozinha num país diferente do seu. Na rede transnacional de estudantes migrantes da universidade estudada, Arry apresentou, até o momento, a recepção mais frágil e dolorosa, com narrativa de desajustes que vão desde a comida até a moradia, passando pela língua e pelo repertório acadêmico, com dificuldades de ajuste até mesmo com a outra leste-timorense que estuda na mesma universidade. Arry é uma ativa participante da pesquisa, sempre disponível para todas as atividades a que foi convidada, além de ela mesma dar ideias de novas atividades desde que entrou.

\subsection{FUNÇÃO METAPRAGMÁTICA E PADRÕES DE SOCIALIZAÇÃO}

Ochs (2000) argumenta que a socialização é uma atividade colaborativa, uma forma contínua de vida que pode ser estudada na forma das trocas comunicativas mais ordinárias. A participação das práticas linguísticas na construção e manutenção das convenções sociais não as impede de ter um papel na invenção de novas regras e de caminhos alternativos para lidar com as condições que promovem ou inibem membros mais e menos experientes no aprendizado uns com os outros, "empregando criativamente recursos linguísticos para navegar e construir a condição humana” (OCHS, 2000, p. 232).

$\mathrm{O}$ que orienta e regula os padrões de socialização em práticas linguísticas vai depender do espectro de variação das atividades em jogo, num contexto situado e delimitado por interesses, mas também daquilo que codifica o contexto-de-ocorrência do evento, calibrando pressupostos e acarretamentos pragmáticos na função metapragmática exercida por recursos linguísticos.

Comparando as duas entrevistas, é possível identificar como a função metapragmática modela a interpretação do processo migratório como dois padrões de socialização com características muito diferentes. 


\section{Excerto $1-\mathrm{J}$. = Entrevistadora. A. = Arry}

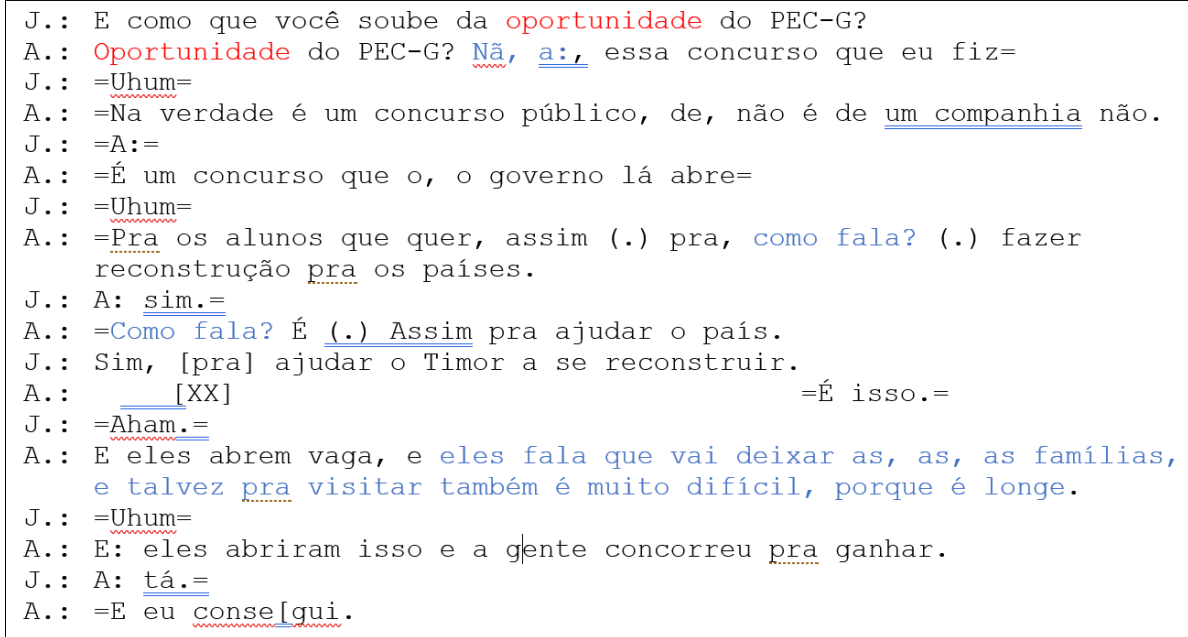

Fonte: AUTOR (2017)

Arry hesita em se referir ao convênio como "oportunidade" - oportunidade do PEC-G? Nã, a:, negando o pressuposto como eu apresento o programa. Durante a conversa truncada, com silêncios e retomadas, sou interpelada a participar da sua narrativa em referência implícita ao potencial do meu repertório - "como fala?". A pergunta, que me interpela, tem aí uma função metapragmática, regulando diferenciação linguística e padrões de socialização exitosos. Entre hesitações e retomadas, informações incompletas e sintéticas, eu procuro manter o fluxo narrativo inserindo elementos de confirmação em turnos contínuos $-=$ Uhum $=,=\mathrm{A}:=, \mathrm{A}: \operatorname{sim} .=,=\mathrm{Aham} .=, \mathrm{A}:$ tá.=. Quando finalmente atendo à posição de mais experiente em "como fala", retextualizando seus quatro turnos anteriores, ela insere a separação da família, a dificuldade de visita e a distância como elementos denotacionais que sustentam a reorientação de "oportunidade" para um tipo de "sofrimento afetivo" pressuposto como necessário para a mobilidade.

\section{Excerto 2 - Ja. = Entrevistadora. Jo.= Jogador.}

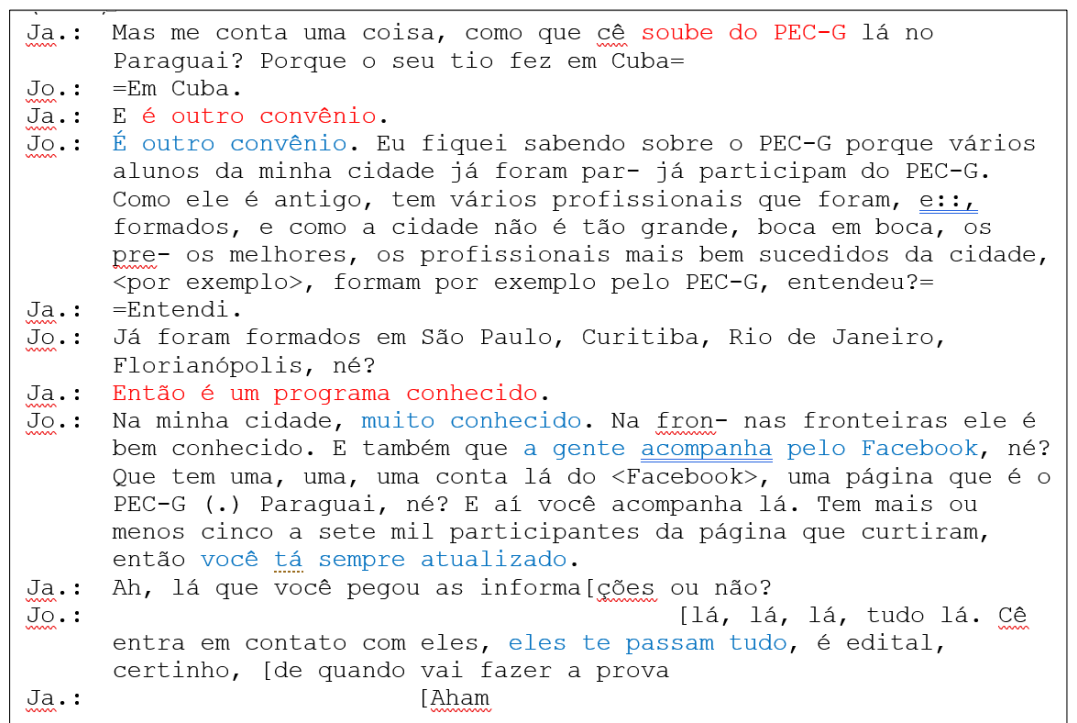

Fonte: AUTOR (2016)

PINTO, Joana Plaza. Corpo como contexto-de-ocorrência de metapragmáticas sobre o português em socializações de estudantes migrantes para o Brasil. Linguagem em (Dis)curso - LemD, Tubarão, SC, v. 18, n. 3, p. 751-768, set./dez. 2018. 
Jogador, por sua vez, orienta sua resposta sobre o convênio do qual faz parte com recursos denotacionais abundantes de progressivo acúmulo de fontes de informações e avaliação positiva dos resultados do PEC-G e das informações disponíveis sobre o programa em sua rede-você tá sempre atualizado, nas fronteiras ele é bem conhecido, você tá sempre atualizado, lá, lá, lá, tudo lá, eles te passam tudo. Ele fala longamente, sem hesitações, e se refere a uma rede transnacional estruturada, com fontes variadas offline - vários alunos da minha cidade, boca em boca, os profissionais mais bem sucedidos, e online-pelo Facebook. Neste excerto sou convocada à participação por um elemento que exerce função metapragmática de enquadrar seu turno contínuo como coerente - Entendeu?

Os dois excertos colocam em evidência que os padrões de socialização como estudantes universitárias(os) migrantes são compreendidos pelo conjunto de itens linguísticos que exercem a função metapragmática de dar coerência a uma posição de falante (in)competente numa certa ordenação indexical. Essa ordenação, no sentido de Silverstein (2003), aponta tanto para eventos e coisas no mundo relacionados ao processo migratório, quanto para quem cada participante é (ou quer parecer/parece ser) e para quem cada um(a) pensa que sua interlocutora imediata é (a entrevistadora) ou poderia ser (interlocutores(as) imaginado(as) em potencial).

Se a função metapragmática ordena o curso da função pragmática (POVINELLI, 2016), então a pergunta de interpelação de Arry e a abundância denotacional de Jogador ordenam a coerência e interpretabilidade do evento narrativo como parte de padrões de socialização diferenciados. No caso de Arry, as hesitações de sua forma narrativa encadeiam as condições inibidoras do aprendizado que marcaram sua socialização. No caso de Jogador, o progressivo acúmulo denotacional encadeia as condições promotoras do aprendizado.

Que diferenças corporais podem ser explicativas dos opostos constituídos nessa comparação de narrativas? A próxima seção explora um pouco mais essa conexão na hierarquização do valor do "português".

\subsection{METAPRAGMÁTICAS EXPLÍCITAS, O VALOR DO "PORTUGUÊS" E OS CORPOS}

Povinelli (2016, p. 211) afirma que "o discurso metapragmático inclui todas as referências implícitas e explícitas a [tais] codificações, usos e contextos, próprios ou impróprios". Nas duas entrevistas, encontramos tal discurso metapragmático, tanto implícito quanto explícito, encadeando predominantemente o lugar de quem fala como falante (in)competente do "português". Mas essa explicitação e essa hierarquização não são separadas dos mesmos elementos que dão coerência aos excertos anteriores e à legibilidade dos corpos em jogo na cena narrativa.

Assim é que, no Excerto 3, Arry avalia o "português" como "muito difícil" para "eles", aí funcionando como uma referência genérica a leste-timorenses, ela inclusa.

Essa dificuldade de Arry é encadeada a uma impossibilidade de qualificação de professores leste-timorenses: um "uso impróprio" que permanece como suspeição - longa pausa de 2.4 segundos - incompleta e fragmentada - um português muito (2.4) não é um (.) um português <XXX> português não é muito - para finalmente ser silenciada em referências explícitas aos usos "próprios" do "português" - aqui no 
Brasil - indiciados com ênfase dupla em seu conhecimento - um professor que sabe muito português mesmo=.

\section{Excerto 3 - J. = Entrevistadora. A.= Arry.}

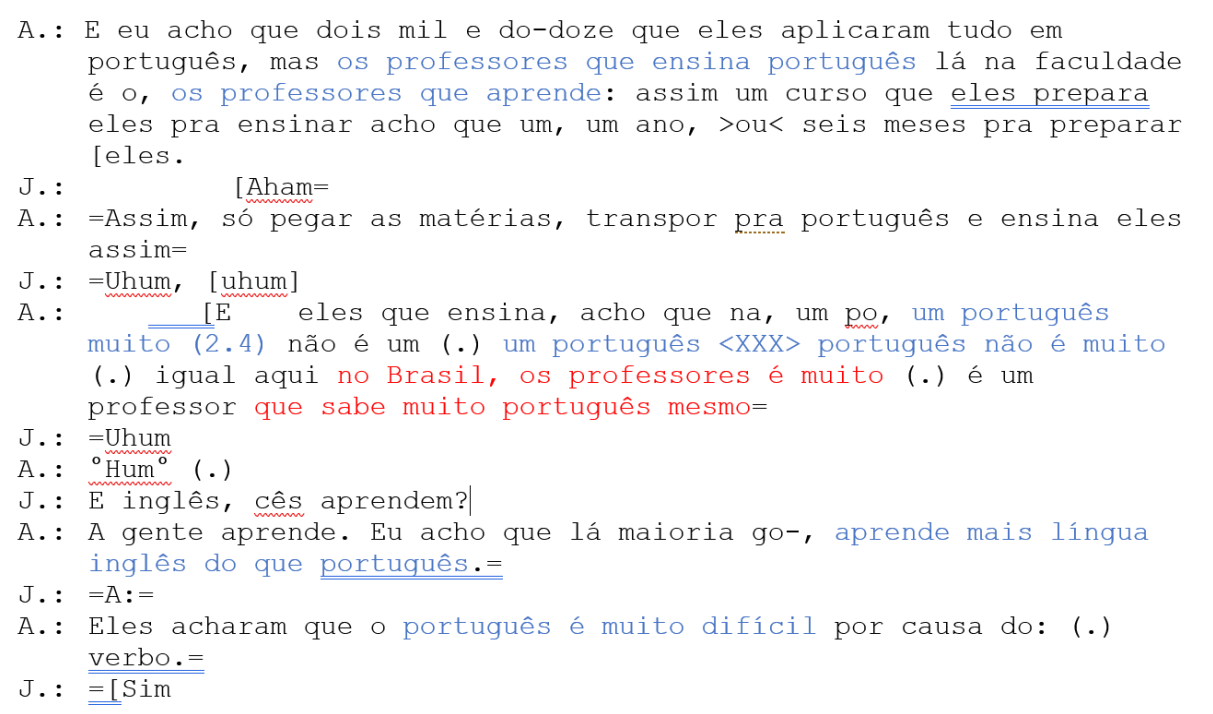

Fonte: AUTOR (2017).

Esse excerto preserva as características recorrentes de nossa interação durante toda a entrevista: Arry usa pausas indiciando hesitações, retomadas indiciando incompletude ou inadequação, e eu mantenho repetidamente os elementos de confirmação em fluxo contínuo de turnos - Uhum, Hum, A:, Sim, na esperança espontânea, ainda que vã, de fazer a narrativa fluir.

As formas linguísticas parecem, então, refletir a incompletude que marca a socialização em "português" para leste-timorenses. A função metapragmática deste excerto é exercida pela própria fragmentação do fluxo narrativo, oferecendo coerência e durabilidade à hierarquização linguística constituída pela metapragmática explícita.

Em sentido contrário, Jogador narra seu aprendizado do "português" como um acúmulo de oportunidades:

\section{Excerto 4 - Ja. = Entrevistadora. Jo.= Jogador.}

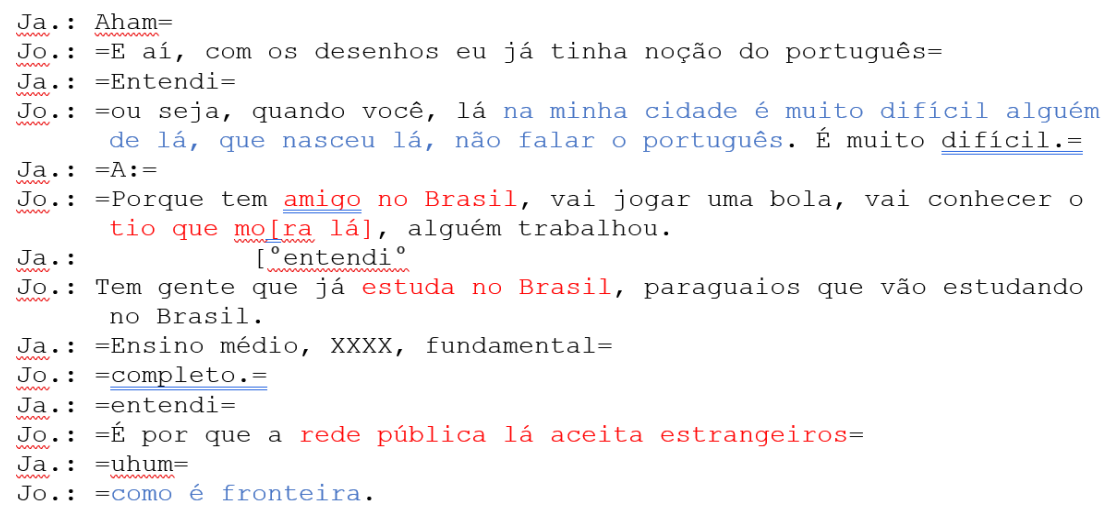

PINTO, Joana Plaza. Corpo como contexto-de-ocorrência de metapragmáticas sobre o português em socializações de estudantes migrantes para o Brasil. Linguagem em (Dis)curso - LemD, Tubarão, SC, v. 18, n. 3, p. 751-768, set./dez. 2018. 


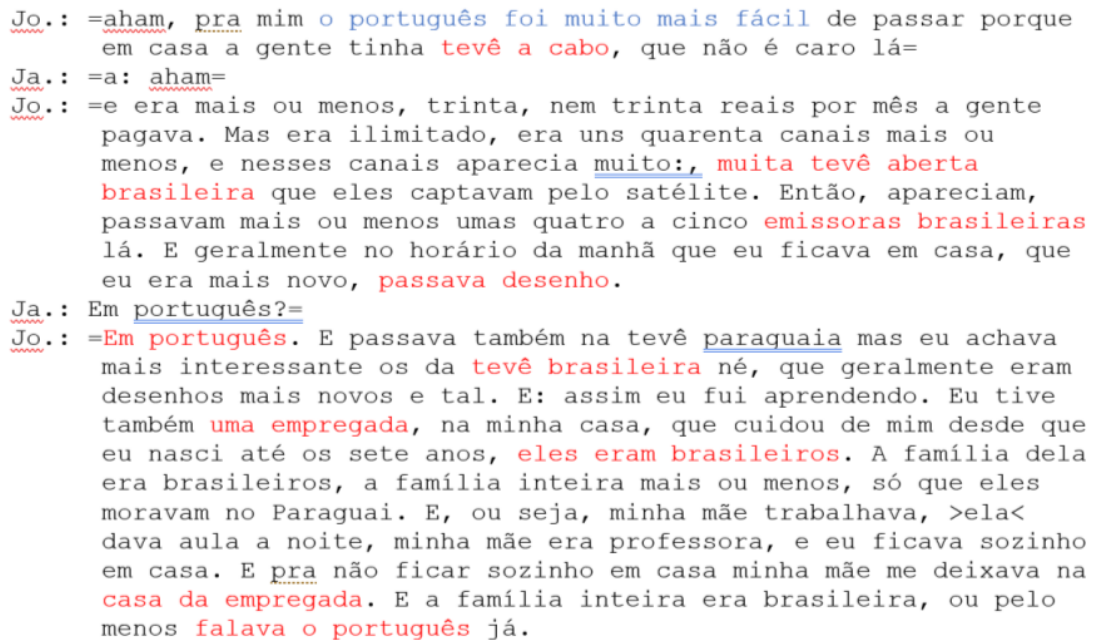

Fonte: AUTOR (2016).

Em casa com a tevê a cabo e a empregada doméstica brasileira; na rua, com os amigos e parentes que moram, estudam e trabalham no Brasil, todos esses espaços narrados são articulados a avaliações de que o difícil é não falar o português, uma inversão da formulação de Arry. E a metapragmática explícita é apresentada em grau ascendente em prelúdio funcional (passar no Celpe-Bras) - o português foi muito mais fácil de passar-e conclusão "cultural" - na minha cidade é muito difícil alguém de lá, que nasceu lá, não falar o português. Nesse ponto, esse padrão de socialização precoce com práticas linguísticas em "português" é atribuído à sua posição na fronteira do Brasil - como é fronteira, como contexto "adequado" às práticas linguísticas desejadas para a mobilidade estudantil-pra mim o português foi muito mais fácil de passar.

Novamente a abundância de elementos denotacionais no decorrer da narrativa dá coerência à sua "facilidade com o português". Aqui, como no Excerto 3, as formas linguísticas refletem o processo de socialização em português, mas em sentido oposto: a narrativa com muitos elementos denotacionais - abundantes e redundantes - exercem a função metapragmática de tornar inteligível a narrativa de múltiplas oportunidades de socialização em português.

Os dois últimos excertos, 5 e 6, mobilizam formas linguísticas que incidem sobre quem fala de maneira direta e explícita, de modo que os recursos metapragmáticos se acumulam como índices do corpo que fala, enquanto o corpo que fala regula os recursos metapragmáticos a serem acionados.

Arry continua insistindo na dificuldade geral dos leste-timorenses em aprender "português", tanto numa avaliação da competência - é muito difícil pra gente aprender o português, a gente não consegue - quanto em oportunidades de socialização-mesmo que na escola a gente aprende português, lá fora a gente já esqueceu.

PINTO, Joana Plaza. Corpo como contexto-de-ocorrência de metapragmáticas sobre o português em socializações de estudantes migrantes para o Brasil. Linguagem em (Dis)curso - LemD, Tubarão, SC, v. 18, n. 3, p. 751-768, set./dez. 2018. 


\section{Excerto 5 - J. = Entrevistadora. A.= Arry.}

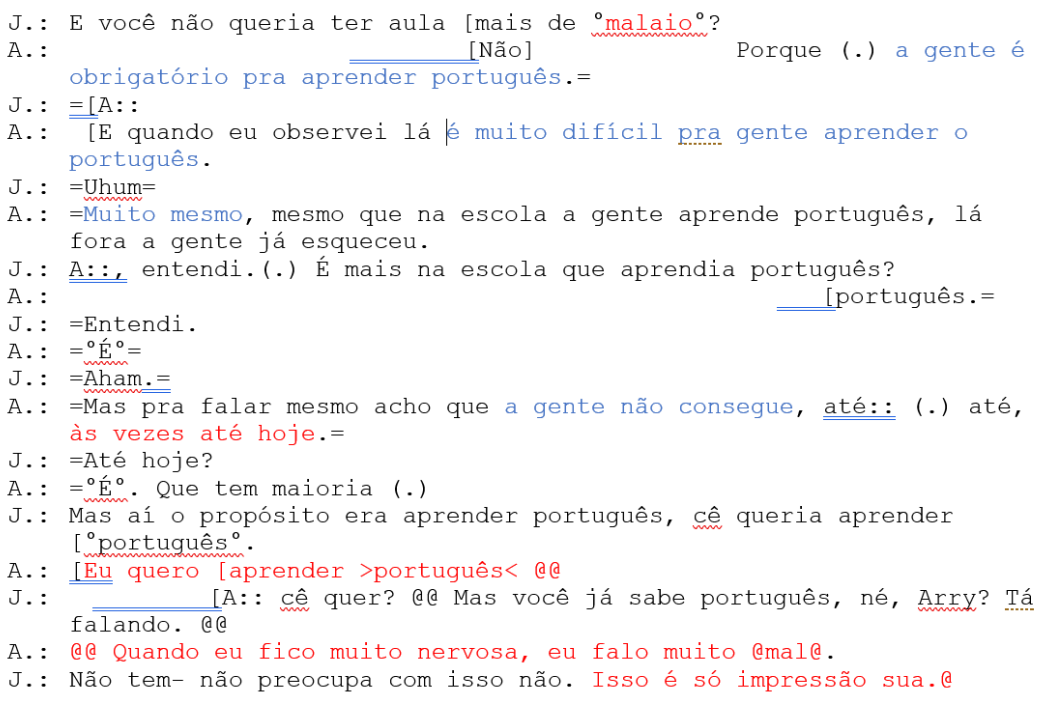

Fonte: AUTOR (2017).

Ochs (2006) destaca o quadro temporal de referência como elemento narrativo fundamental na costura entre experiência, memória, antecipação e imaginação. Mas a autora também chama atenção para uma tensão na linearidade narrativa: eventos passados podem levar tanto a uma projeção de futuro, quanto a especulação sobre o futuro pode levar à retomada de eventos passados. É exatamente esta tensão que está colocada na alternância de tempos narrativos no Excerto 5, presente-passado-presente-futuro. Alguém poderia argumentar que é o "desconhecimento" de Arry das formas temporais em "português" que produz essa alternância, mas certamente não se pode negar que ela também usa um dêitico de tempo - até hoje - para ordenar sua narrativa, regulando eventos temporais na construção de sua posição como uma falante "incompetente" do "português". Este "até" leva a avaliação do seu aprendizado como ainda em andamento, envolto em afetos que colocam o valor do que ela diz no conjunto das emoções da vida cotidiana em seu contexto de mobilidade.

Os quatro últimos turnos do Excerto 5 encadeiam uma negociação metapragmática explícita sobre a hierarquização naturalizada. O riso preenche os quatro turnos, eu e ela nos esforçando para encontrar o lugar do "português" nos espelhos dos corpos que falam, corpo inadequado/autorizado. Se

\footnotetext{
o que perturba a língua social e a transforma em língua individual não é a linguagem por ela mesma, mas, pelo menos em parte, na interioridade pré e não linguística, os vínculos afetivos e corporais, as necessidades, os imaginários e as superfícies que a linguagem marca/é marcada e contraria/é contrariada. (POVINELLI, 2016, p. 228)
}

então, os risos marcam as formas metapragmáticas explícitas com os vínculos afetivos e corporais construídos ao longo da entrevista em particular, mas também da etnografia em geral, confrontando os afetos que regulam as performances linguísticas e suas avaliações - uma projeção metapragmática para uma pragmática do corpo marcado pela "inadequação" da língua. 
Assim como Arry, Jogador, no Excerto 6, também racionaliza seus usos prévios, no entanto com enquadre positivo, já que "estudar o português" não é necessário - não é que você estuda o português, como a gente é, mora na fronteira, pra falar não tem dificuldade. Mas ele também confronta suas próprias “inadequações" sem indiciar diretamente com o "português" - ela corrige sua, sua escrita, pra escrever é outra história.

\section{Excerto 6 - Ja. $=$ Entrevistadora. Jo.= Jogador.}

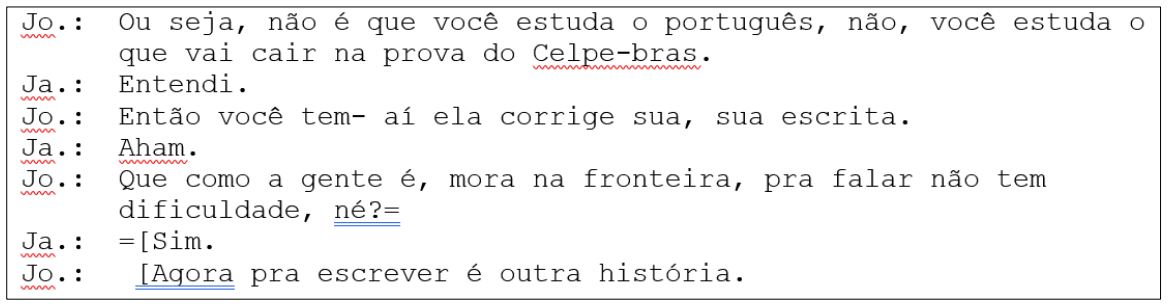

Fonte: AUTOR (2016)

A escrita encontra uma orientação explícita na convergência pressuposta oralescrito: em sabendo falar "o português" reconhecido como "da fronteira", ele precisa destacar as linhas narrativas diferentes de suas práticas orais e de práticas escritas, respondendo ao valor destas últimas na socialização institucional universitária. A escrita, em oposição à fala, é outra história. Como sintetiza Signorini (2002, p. 120-121), "no que se refere às formas de pressão sobre o falante, quanto mais forte a 'cultura de padronização', nos termos de Silverstein (1996), maior a polarização diglóssica entre domínios de uso e funções, e entre formas e códigos comunicativos".

\section{PROJEÇÕES METAPRAGMÁTICAS EM CORPOS COMO CONTEXTO-DE-OCORRÊNCIA}

Nessas narrativas circunscritas numa rede de mobilidade transnacional programada e institucionalizada, recursos metapragmáticos remetem aos discursos sobre diferentes repertórios de língua projetados como uso do "português".

Entender as projeções metapragmáticas como certas regulações metapragmáticas fortemente explícitas projetadas por categorias pragmáticas fez com que eu prestasse atenção às formas linguísticas que assumem uma função metapragmática nessas narrativas.

Se a "metapragmática [...] modela as relações de sinal de indexação no contexto como segmentos de evento de texto de interação" (SILVERSTEIN, 1993, p. 36), se "a função metapragmática serve para regular índices dentro de evento(s) interpretável(eis) de tal e tal tipo que o uso da linguagem na interação constitui (consiste de)" (SILVERSTEIN, 1993, p. 37) e se "os próprios segmentos de texto interativos metapragmaticamente funcionais têm uma dimensão pragmática" (SILVERSTEIN, 1993, p. 40), a dimensão pragmática também implica uma metapragmática, como camadas sobrepostas, cujo funcionamento só é possível ver no evento comunicativo. 
[a] função metapragmática assegura que, na maior parte das trocas comunicacionais e, de fato, na própria "cultura", com as identidades que ela define, como, por exemplo, gênero se faça a experiência de uma totalidade estável e suficientemente coerente. (POVINELLI, 2016, p. 211-212)

As hesitações e as condições inibidoras, por um lado, e o progressivo acúmulo denotacional e as condições promotoras, por outro, se inserem, inevitavelmente, na totalidade da "cultura" que regula hierarquizações linguísticas e categorias corporais de diferença como parte coerente dos sucessos e fracassos (narrativos e migratórios). Ancorados no mundo material, os recursos metapragmáticos (função metapragmática ou metapragmáticas explícitas) e as práticas de socialização não são legíveis sem o corpo que fala no excesso do ato comunicativo (BUTLER, 1997; FELMAN, 1980).

Portanto, o que instiga a pensar esses extremos opostos é como o corpo se constitui como condição para se dizer certas coisas, ao mesmo tempo que é constituído pelas coisas que diz. É por isso que defendo a inclusão em nossas análises de uma ordenação indexical do corpo que fala, na medida em que se projeta e projeta suas(seus) interlocutoras(es). Tal ordenação pressupõe, ao final da linha abstrata que conecta os vários níveis semióticos pragmáticos e metapragmáticos (SILVERSTEIN, 2003), agentes sociais, encarnados em corpos que são indiciados por formas linguísticas consideradas apropriadas e efetivas ao corpo como contexto-de-ocorrência, nomes, pronomes, adjetivos e sentenças inteiras como "ela", “ele”, "mulher", "homem”, “paraguaio", "lestetimorense", "jovem", "falante bilíngue do português", "mal falante do português", e assim por diante.

\footnotetext{
O espaço colocado pela denotação e pela indexicalidade chega à categoria de função social pelo intermédio de agentes sociais que, muitas vezes sem saber, se valem da função metapragmática da linguagem e de um aspecto ou outro dos signos gramaticais para ordenar as atualidades indexais e semânticas. (POVINELLI, 2016, p. 217)
}

Assim, os dois casos nos ajudam a notar quais recursos metapragmáticos remetem aos diferentes repertórios de língua projetados como uso do "português" e fazem referências implícitas e explícitas a codificações, usos e contextos próprios e impróprios das práticas linguísticas indiciadas como pressupostas, prévias e encadeadas em eventos narrados como necessários e/ou desejados para a vinda ao Brasil.

Nesse sentido, os regimes metadiscursivos sobre o acesso à universidade brasileira por estrangeiras(os) fazem referência a normas linguísticas, ideológicas e institucionais, destacando-se a questão da socialização sobre as normas institucionais preparatórias como índice do sucesso da trajetória de acesso. Essa socialização e o sucesso da trajetória são fundamentais nas formulações explícitas sobre o valor do "português" de quem narra e sobre a continuidade da experiência atual linguística e estudantil.

Eu gostaria de terminar relembrado que as metapragmáticas produzidas no curso das narrativas - perguntas interpelativas, abundância denotacional, organização temporal, vinculações afetivas das formas interacionais, distinção oralidade-escrita - não apenas orientam a interpretação dos valores linguísticos do que é dito, para a entrevistadora, motivada por uma pesquisa etnográfica e em circunstâncias micro e macrocontextuais 
definidas numa escala TempoEspaço ${ }^{7}$, mas também a interpretação da ordenação indexical na qual o corpo que fala (Arry ou Jogador) se projeta e projeta suas/seus interlocutoras/es.

\begin{abstract}
Cada um imbui o passado com significado - pessoal e coletivo - e, ao fazê-lo, constrói mundos da vida presentes e projetados. Sujeito a desafiar tanto de fora (ou seja, outros) e de dentro (ou seja, eus múltiplos e conflitantes), esses mundos não são totalmente coerentes e estão sempre evoluindo. Sempre que os narradores lançam uma história, eles se abrem para a reconstrução. Para o melhor e o pior, as práticas narrativas cotidianas confrontam os interlocutores com emoções e idéias imprevistas e, em última análise, com eus imprevistos. (OCHS; CAPPS, 1996, p. 37)
\end{abstract}

Seria ótimo que essas narrativas fossem a costura reconstruída de cada evento e ação, de modo que oferecessem novos contextos-de-ocorrência para o corpo que fala e age em mobilidade. Parafraseando Povinelli (2016), a linguagem pode denotar e fixar a ordenação indexical do corpo falante e do valor das suas práticas linguísticas, mas as mesmas projeções metapragmáticas podem fornecer os meios de sua ambiguidade, insegurança e indeterminação, e, desse modo, reinvenção.

\title{
REFERÊNCIAS
}

BAUGH, John. Linguistic Profiling. In: MAKONI, Sinfree; SMITHERMAN, Geneva; BALL, Arnetha F.; SPEARS, Arthur K. (Ed.). Black Linguistics: language, society and politics in Africa and the Americas. New York: Routledge, 2003. p. 155-168.

BLOMMAERT, Jan. Contexto é/como crítica. In: SIGNORINI, Inês (Org.). Situar a linguagem. São Paulo: Parábola, 2008. p. 91-115.

Chronotopes, Scales, and Complexity in the Study of Language in Society. Annual Review of Anthropology, v. 44, p. 105-116, 2015.

BLOMMAERT, Jan; JIE, Dong. Ethnographic fieldwork. A beginner's guide. Bristol: Multilingual Matters, 2010.

BORBA, Rodrigo. (Des)aprendendo a "ser": trajetórias de socialização e performances narrativas no Processo Transexualizador. 2014. 206 f. Tese (Doutorado em Linguística Aplicada) - Faculdade de Letras, Universidade Federal do Rio de Janeiro, Rio de Janeiro, 2014.

BRAH, Avtar. Diferença, diversidade, diferenciação. Cadernos Pagu, Campinas, n. 26, p. 329-376, 2006. BRIGGS, Charles L. Mediating infanticide: theorizing relations between narrative and violence. Cultural Anthropology, v. 22, n. 3, p. 315-356, 2007.

BUCHOLTZ, Mary. The Politics of Transcription. Journal of Pragmatics, v. 32, p. 1439-1465, 2000.

BUTLER, Judith. Excitable speech. A politics of performative. New York: Routledge, 1997.

FELMAN, Shoshana. Le scandale du corps parlant: Don Juan avec Austin ou la seduction en deux langues. Paris: Édtions du Seuil, 1980.

HYMES, Dell. Ethnography, linguistics, narrative inequality. Toward a understanding of voice. New York: Taylor \& Francis, 1996.

MAKONI, Sinfree; PENNYCOOK, Alastair. Disinventing and reconstituting languages. Clevedon: Multilingual Matters, 2007.

MIGNOLO, Walter D. Histórias locais/ Projetos globais: Colonialidade, saberes subalternos e pensamento liminar. Trad.: Solange Ribeiro de Oliveira. Belo Horizonte: Editora da UFMG, 2003.

\footnotetext{
${ }^{7}$ No sentido argumentado por Blommaert (2015).

PINTO, Joana Plaza. Corpo como contexto-de-ocorrência de metapragmáticas sobre o português em socializações de estudantes migrantes para o Brasil. Linguagem em (Dis)curso - LemD, Tubarão, SC, v. 18, n. 3, p. 751-768, set./dez. 2018.
} 
MOITA LOPES, Luiz Paulo (Org.). Português no século XXI: ideologias linguísticas. São Paulo: Parábola Editorial, 2013.

OCHS, Elinor. Indexing gender. In: DURANTI, Alessandro; GOODWIN, Charles (Ed.). Rethinking context. Language as an interactive phenomenon. Cambridge: Cambridge University Pressa, 1992. p. 335-358.

. Narrative lessons. In: DURANTI, Alessandro (Ed.). A Companion to Linguistic Anthropology. New Jersey: Blackwell Publishing Ltd, 2006. p. 269-289.

Socialization through Language and Interaction: a theoretical introduction. Issues in Applied Linguistics, v. 2, n. 2, p. 143-147, 1991.

Socialization. Journal of Linguistic Anthropology, v. 9, n. 1-2, p. 230-233, 2000.

OCHS, Elinor; CAPPS, Lisa. Narrating the self. Annual Review of Anthropology, n. 25, p. 19-43, 1996.

PISCITELLI, Adriana. Interseccionalidades, categorias de articulação e experiência de migrantes brasileiras. Sociedade e Cultura,v. 11, n. 2, p. 263-274, 2008.

POVINELLI, Elizabeth. Pragmáticas íntimas: linguagem, subjetividade e gênero. Trad.: Joana Plaza Pinto. Revista de Estudos Feministas, v. 24, n. 1, p. 205-237, 2016.

SALES JR., Ronaldo. 2006. Democracia racial: o não-dito racista. Tempo social, v. 18, n. 2, p. 229-258.

SCOLLON, Ron; SCOLLON, Suzie Wong. Discourses in place. Language in the material world.

London e New York: Routledge, 2003.

SIGNORINI, Inês. Por uma teoria da desregulamentação linguística. BAGNO, Marcos (Org.). Linguística da norma. São Paulo: Edições Loyola, 2002. p. 93-125.

SILVERSTEIN, Michael. Indexical order and the dialectics of sociolinguistic life. Language \& Communication, n. 23, p. 193-229, 2003.

Metapragmatic discourse and metapragmatic function. In: LUCY, John (Ed.). Reflexive

language, reported speech and metapragmatics. Cambridge: Cambridge University Press, 1993. p. 33-58.

\section{CONVENÇÕES DE TRANSCRIÇÃO}

Cada linha representa um aspecto da fala em interação:

entonação descendente

entonação ascendente

alongamento de som

entonação contínua

risada

Exalação (riso leve, suspiro); cada letra marca um pulso

tosse

fala inaudível

*־. fricativa retroflexa surda

interrupção abrupta da fala

$=\quad$ turnos contínuos

[ ] fala sobreposta

$<$ fala acelerada

$>\quad$ fala desacelerada

$\circ \quad$ volume mais baixo

* $\quad$ sons não falados percussivos

(n.n) medida de silêncio em segundos e décimo de segundos

(.) silêncio de menos de 2 décimos de segundo

(( )) dúvida na transcrição

( ) comentário de quem transcreve 
Title: Body as context-of-occurrence of metapragmatics about Portuguese in socializations of migrant students to brazil

Author: Joana Plaza Pinto

Abstract: This paper analyzes metapragmatic projections about Portuguese in migrant students' narratives in Brazil. Yielded in longitudinal ethnographic research, the narratives focused on the migratory trajectories of coming, reception and permanence and their positions in front of the Portuguese. For this analysis, Povinelli's interpretations of metapragmatics and Ochs's studies on language socialization are central. The analysis points out that the socialization of institutional norms as fundamental in the explicit formulations on the value of Portuguese used by the narrator and the evaluation of the student experience. These metapragmatics guide the interpretation of the linguistic values of what is said, to whom, why and in what circumstances, while the speaking body projects itself and projects its interlocutors in this interpretation. The body is a context-of-occurrence for semiotic resources - the space where conditions are constituted to say certain things and the space that is constituted by the things that are said.

Keywords: Student migration. Body. Socialization. Metapragmatics. Portuguese.

Título: Cuerpo como contexto-de-ocurrencia de meta pragmáticas sobre el portugués en socializaciones de estudiantes migrantes a Brasil

Autora: Joana Plaza Pinto

Resumen: Este artículo analiza proyecciones meta pragmáticas sobre el portugués en narrativas de estudiantes migrantes en Brasil. Producidas en investigación etnográfica longitudinal, las narrativas enfocaron las trayectorias de venida, recepción y permanencia migratoria y sus posiciones delante del portugués. Para esta análisis, son centrales las interpretaciones de Povinelli sobre los estudios meta pragmáticos, y de Ochs sobre socialización por el lenguaje. El análisis apunta que la socialización de las normas institucionales es fundamental en las formulaciones explícitas sobre el valor del portugués de quien narra y la evaluación de la experiencia del estudiante. Esas meta pragmáticas orientan la interpretación de valores lingüísticos del que es dicho, para quien, por qué y en qué circunstancias, mientras el cuerpo que habla se proyecta y proyecta sus interlocutores en esa interpretación. El cuerpo es un contexto-de-ocurrencia para los recursos semióticos - el lugar en que se constituyen condiciones para decir ciertas cosas y el lugar que es constituido por las cosas que se ha dicho.

Palabras-clave: Migración de estudiantes. Cuerpo. Socialización. Meta pragmática. Portugués.

AGRADECIMENTOS

Agradeço às duas pessoas que se interessaram e engajaram nas atividades da pesquisa, tanto durante as entrevistas quanto em ocasiões diversas ao longo desses mais de dois anos de convivência. Agradeço igualmente a Ana Luiza Krüger Dias e a Letícia Leme da Cruz, pelas reflexões compartilhadas durante a escuta coletiva destas entrevistas. Suas contribuições foram muito importantes para o direcionamento desta análise.

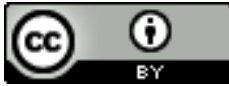

Este texto está licenciado com uma Licença Creative Commons Atribuição 4.0 Internacional.

PINTO, Joana Plaza. Corpo como contexto-de-ocorrência de metapragmáticas sobre o português em socializações de estudantes migrantes para o Brasil. Linguagem em (Dis)curso - LemD, Tubarão, SC, v. 18, n. 3, p. 751-768, set./dez. 2018. 